\title{
DYNAMIC CONTOUR TONOMETRY AND GOLDMAN APPLANATION TONOMETRY IN EYES WITH KERATOCONUS
}

\author{
Jackson Barreto Jr., Mirko Babic, Roberto Murad Vessani, Remo Susanna Jr.
}

\begin{abstract}
Barreto Jr. J, Babic M, Vessani RM, Susanna Jr. R. Dynamic contour tonometry and goldman applanation tonometry in
\end{abstract} eyes with keratoconus. Clinics. 2006;61(6):511-4.

PURPOSE: The dynamic contour tonometer is a nonapplanation contact tonometer designed to be largely independent of the structural properties of the cornea. Theoretically, it may measure intraocular pressure most accurately in abnormally thinner corneas. This study compares intraocular pressure measurements by dynamic contour tonometry with Goldman applanation tonometry in eyes with normal corneas and eyes with advanced keratoconus.

METHODS: A comparative case series. Subjects underwent intraocular pressure measurements by dynamic contour tonometry, Goldman applanation tonometry, ultrasonic pachymetry, and slit scanning topography. Exclusion criteria: any ocular pathology other than keratoconus, previous corneal or refractive surgery, stromal scarring due to acute hydrops, or any other corneal opacities. RESULTS: Ten patients with keratoconus were included in Group A, and 12 normal patients composed Group B according to the pre-established criteria. The mean Goldman tonometry measurement in group A was $10.3 \pm 1.8 \mathrm{~mm} \mathrm{Hg}$ and group B was $14.3 \pm$ $0.75 \mathrm{~mm} \mathrm{Hg}$. $(P=0.024)$. In group A, the mean measurement with the dynamic contour tonometer was $14.6 \pm 2.09 \mathrm{~mm} \mathrm{Hg}$, and in group $\mathrm{B}$, it was $17.4 \pm 3.1 \mathrm{~mm} \mathrm{Hg}(P=0.026)$. The difference between both methods of measurement in group A was statistically significant $(P<0.0002)$.

CONCLUSION: Intraocular pressure readings with dynamic contour tonometry in the keratoconus group were significantly higher than Goldman measurements and lower when compared to the control group. As there are no published manometric studies in eyes with keratoconus, these lower intra-ocular readings with the dynamic contour tonometry could be related to the discrepancy between the radius of corneal curvature and its tip, the significant thinning of the cornea, or other corneal biomechanical abnormalities related to advanced keratoconus.

KEYWORDS: Intraocular Pressure. Keratoconous. Applanation Tonometry. Dynamic Contour Tonometry. Corneal Thickness. Goldman.

\section{INTRODUCTION}

The effect of central corneal thickness (CCT) on the accuracy of intraocular pressure (IOP) measurement by applanation tonometry was first suggested by Goldmann in 1957. ${ }^{1}$ Later reports evaluated this possibility and suggested that Goldmann tonometry may underestimate IOP in eyes

Department of Ophthalmology, São Paulo University Medical School - São Paulo/SP, Brazil.

Email: jackbj@terra.com.br

Received for publication on April 17, 2006.

Accepted for publication on July 31, 2006. with thinner corneas and hyperestimate this parameter in eyes with thicker corneas. ${ }^{2-4}$ With the advent of excimer laser refractive surgery, the number of iatrogenically thinned corneas has increased in the last 15 years. ${ }^{5}$ This new generation of patients faces the need of an accurate IOP measurement. Similarly, patients with structurally normal thinner corneas and progressive field loss as may occur in normal tension glaucoma need reliable IOP measurements in order to establish their target pressures.

Attempts have been made to circumvent the effect of CCT by methods of IOP measurement that theoretically should be less affected by CCT. ${ }^{4-6}$ The Pascal ${ }^{\circledR}$ dynamic contour tonometer (DCT) is a nonapplanation contact to- 
nometer designed to be largely independent of the structural properties of the cornea (Swiss Microtechnology $\left.{ }^{\circledR}\right)^{7}$ The DCT has a specially designed tip with a concave contact surface of $10.5 \mathrm{~mm}$ radius that matches the contour of the cornea. Pressure on both sides of the cornea is equalized as the cornea takes the tip contour, and a pressuresensitive area in the center of the contour surface with a built-in microprocessor provides a direct and continuous transcorneal measurement of IOP that is independent of corneal properties. All forces exerted on the cornea are compensated by a tight-fitting shell created by the tip of the tonometer. Theoretically, DCT may measure IOP most accurately in abnormally thinner corneas.

Keratoconus is an ectatic degeneration of the cornea characterized by progressive thinning of its central region and significant increase in its curvature. ${ }^{8}$ Several studies have demonstrated the influence of altered biomechanical properties of ectatic corneas on IOP readings. Bohm et $\mathrm{al}^{9}$ showed that Goldmann applanation tonometry (GAT) measurements were significantly reduced when measuring IOP at the conus peak in comparison to the unaffected area of the cornea in patients with keratoconus. Brooks et $\mathrm{al}^{10}$ also correlated IOP measurements with corneal thinning and confirmed that GAT measurements were significantly reduced at the apex of the cone. Furthermore, that study found that corneal thinning was not the only factor, as IOP measurements were also reduced in patients with large sagging cones without corneal thinning. ${ }^{10} \mathrm{We}$ found no recently published data regarding to the possible influence of ectatic corneas on IOP readings obtained by DCT. Our study was conducted to compare IOP measurements by DCT with those by GAT in eyes with normal corneas and eyes with keratoconus.

\section{METHODS}

This was a prospective comparative case series. Patients with diagnoses of keratoconus were recruited from the list of patients waiting for penetrating keratoplasty. A control group of normal subjects was obtained from the General Ambulatory of Ophthalmology. The research followed the tenets of the Declaration of Helsinki, and informed consent was obtained after explanation of the nature and possible consequences of the study.

The keratoconus diagnosis was defined by clinical examination and confirmed by slit scanning topography using the Orbscan IIz (Bausch \& Lomb®; Rochester, New York, USA). Only cases of central steepening with coincidental thinnest point (nipple morphology) were included in the keratoconus group. Subjects with any other ocular pathology, previous corneal or refractive surgery, stromal scarring due to acute hydrops, or any other corneal opacities were excluded.

Subjects meeting eligible criteria underwent IOP measurement by Goldmann applanation tonometry (GAT) and by dynamic contour tonometry (DCT), ultrasonic pachymetry, and slit scanning topography (Orbscan IIz).

The examiner performing the Orbscan was different from the ones who performed the IOP measurements in order to avoid bias by previous knowledge regarding the keratoconus cases.

The IOP measurement was first obtained by GAT in the central cornea. The mean of 2 consecutive measurements was recorded. If the first 2 readings differed by more than $2 \mathrm{~mm} \mathrm{Hg}$, a third reading was taken. Goldmann applanation tonometry measurements followed the guidelines from the Eye Care Technology Forum for standardizing the measurement of intraocular pressure for clinical research. ${ }^{10}$

After the GAT readings, IOP was measured with DCT. The DCT is mounted on the slit-lamp similar to that used in the GAT readings and provides an absolute numerical output of IOP after coming in contact with the cornea for about 5 seconds. A 'Q' value is also displayed with the DCT measurements; it refers to the quality of data obtained. The ' $\mathrm{Q}$ ' value is graded from 1 to 5 (Q1 is optimum; 2 and 3 are acceptable; 4 and 5 are unacceptable, should be discarded and the measurement repeated). In this study, 2 consecutive DCT measurements were performed in all eyes, and only Q1 and Q2 measurements were accepted. The examiner performing the DCT measurement was different from the one who performed the GAT measurement.

Lastly ultrasonic pachymetry was performed. Three readings were taken, and the mean value was obtained for each subject.

The mean IOP per group was calculated for both GAT and DCT, and the differences between these mean values were compared in each group. The statistical tests used were the 2-tailed tests, the $t$ test and the Fischer test, using the SPSS software (version 13.0 for Windows). A $P$ value less than 0.05 was considered statistically significant.

\section{RESULTS}

A total of 49 patients was examined. Ten out of 32 patients with keratoconus (Group A) and 12 out of 17 patients seen at the General Ambulatory of Ophthalmology (Group B) were included in the study according to the pre-established criteria.

Demographic data including gender, age, and race are presented in Table 1. No significant difference was found regarding gender, age, or race between groups $(P=0.3 ; P$ $=0.1 ; P=0.7$; respectively). 
Table 1 - Demographic data for groups A and B

\begin{tabular}{lccccccc}
\hline & \multicolumn{2}{c}{ Gender $(\mathrm{n} / \%)$} & \multicolumn{2}{c}{ Age } & \multicolumn{2}{c}{ Race $(\mathrm{n} / \%)$} \\
Male & Female & $($ mean \pm SD) & Caucasians & Africans & Asians & Mixed \\
\hline Group A & $3(30 \%)$ & $7(70 \%)$ & $22 \pm 6.8$ & $5(50 \%)$ & $2(20 \%)$ & - & $3(30 \%)$ \\
Group B & $6(50 \%)$ & $6(50 \%)$ & $27 \pm 6.8$ & $6(50 \%)$ & $1(8.3 \%)$ & $1(8.3 \%)$ & $4(33.3 \%)$ \\
\hline
\end{tabular}

In group $\mathrm{A}$, the mean keratometry (flattest reading) was $60.6 \pm 9.5 \mathrm{D}$ (diopters) (range, 49.4-81.0 D) and group B was $42.7 \pm 1.7 \mathrm{D}$ (range, $39.8-45.3 \mathrm{D}$ ). This difference was statistically significant $(P<0.0001)$. The mean CCT was $387.8 \pm 53.3 \mu \mathrm{m}$ (range, $298-468 \mu \mathrm{m}$ ) in group A compared to $551 \pm 15.3 \mu \mathrm{m}$ (range, $530-576 \mu \mathrm{m}$ ) in group B. This difference was statistically significant $(P<0.0001)$.

The mean GAT measurement in group A was $10.3 \pm 1.8$ $\mathrm{mm} \mathrm{Hg}$ and in group B was $14.3 \pm 0.75 \mathrm{~mm} \mathrm{Hg}$. A significant difference was found $(P=0.024)$. In group A, the mean DCT measurement was $14.6 \pm 2.09 \mathrm{~mm} \mathrm{Hg}$, and in group $\mathrm{B}$, the mean DCT measurement was $17.4 \pm 3.1 \mathrm{~mm} \mathrm{Hg}$. This difference was also statistically significant $(P=0.026)$. The ranges for GAT and DCT measurements for group A and B are shown in Figure 1. The difference between GAT and DCT measurements for group A is shown in Figure 2.
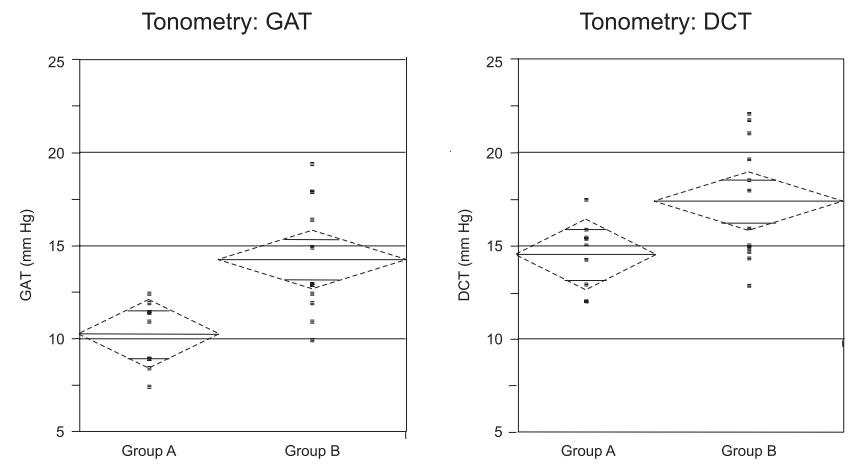

Figure 1 - The range of mean intraocular pressure (IOP) readings by Goldman applanation tonometry (GAT) and by dynamic contour tonometry (DCT) for groups A and B

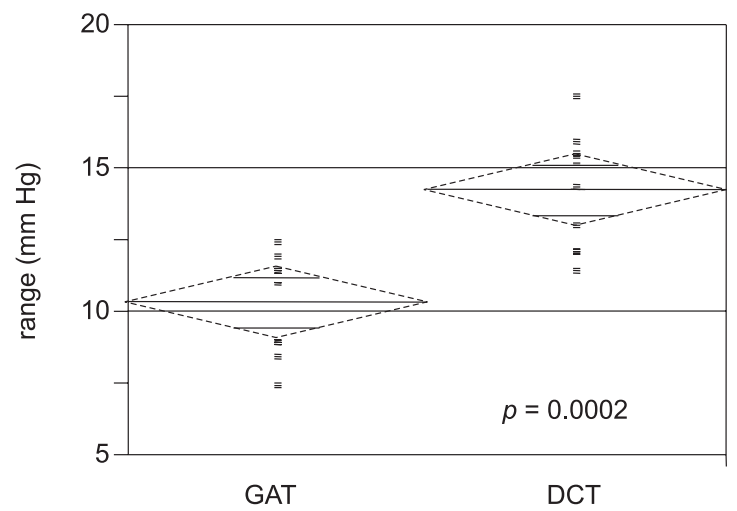

Figure 2 - The difference of mean intraocular pressure (IOP) readings by Goldman applanation tonometry (GAT) and dynamic contour tonometry (DCT) for group A

\section{DISCUSSION}

Since the last results of the Ocular Hypertension Treatment Study were published, CCT has received much attention because of its influence on measurement of IOP. ${ }^{12}$ Being the gold standard for clinical measurement of IOP, GAT assumes that every cornea has a standard corneal stiffness or resistance that tends to oppose corneal flattening in a determined surface area (ImbertFick law). ${ }^{1}$ However, thinner corneas tend to be more elastic and may lead to underestimation of GAT IOP measurements. ${ }^{2-5}$ This fact is clearly demonstrated in Figure 1, which showed a significant difference in GAT measurements between eyes with keratoconus and normal eyes $(P=0.024)$. A manometric study by Ehlers and Hansen reported an underestimation of IOP in normal thin corneas. The underestimation of IOP measurements was around $5 \mathrm{~mm} \mathrm{Hg}$ per $70 \mu \mathrm{m}$ change in CCT. ${ }^{13} \mathrm{In}$ that study, no information about eyes with ectatic corneas was provided.

In our study, we also observed that eyes with keratoconus had lower IOP readings with the DCT than normal eyes (Figure 1-DCT). This finding was not expected, since DCT should be largely independent of the biomechanical corneal properties. ${ }^{5-7}$ One hypothesis for this result is that IOP is truly lower in eyes with keratoconus compared to normal eyes. Another possibility could be related to measurement limitations of the DCT in cases of keratoconus. These limitations could be related to the discrepancy between the radius of corneal curvature in keratoconus (elevated keratometry) and the DCT tip, the significant thinning of these corneas, or other corneal biomechanical abnormalities (such as abnormal hysteresis). Until now there have been no published manometric studies in eyes with keratoconus to prove that the "true IOP" is lower in these patients.

In spite of the low IOP readings with the DCT in the keratoconus group, they still are significantly higher than the GAT measurements in this group, as shown in Figure 1.

In summary, IOP readings by DCT were significantly lower in eyes with keratoconus than in controls $(P=0.026)$. Manometric studies in eyes with keratoconus would be helpful to elucidate this finding and to determine the value of DCT in eyes with this corneal pathology. 
Barreto Jr. J, Babic M, Vessani RM, Susanna Jr. R. Tonometria de contorno dinâmico e tonometria de aplanação de goldman em olhos com ceratocone. Clinics. 2006;61(6):511-4.

OBJETIVO: O tonômetro de contorno dinâmico é um aparelho de contato e não-aplanação projetado para ser independente das propriedades estruturais da córnea. Teoricamente, ele mede de forma mais precisa a pressão intra-ocular em córneas muito finas. Este estudo compara as medidas de pressão intra-ocular pelo tonômetro de contorno dinâmico com a tonometria de aplanação de Goldman em olhos normais e em olhos com ceratocone avançado.

MÉTODOS: uma série comparativa de casos. Pacientes foram submetidos às medidas de pressão intra-ocular por ambos os métodos mencionados, paquimetria ultrassônica e topografia corneana de varredura. Critérios de exclusão: qualquer patologia ocular exceto ceratocone, cirurgia ceratorrefrativa prévia, opacidade estromal resultante de hidropsia aguda ou qualquer outra opacidade corneana.

RESULTADOS: Dez pacientes com ceratocone foram incluídos no grupo A e 12 pacientes com córneas normais no grupo B conforme os critérios pré-estabelecidos. A média das medidas da tonometria de Goldman no grupo A foi de $10.3 \pm 1.8 \mathrm{mmHg}$ e no grupo $\mathrm{B}$ de $14.3 \pm 0.75 \mathrm{mmHg}$. $(\mathrm{p}=0,024)$. No grupo $\mathrm{A}$, a média das medidas com o tonômetro de contorno dinâmico foi de $14.6 \pm 2,09 \mathrm{mmHg}$ e, no grupo $\mathrm{B}, 17,4 \pm 3,1 \mathrm{mmHg}(\mathrm{p}=0,026)$. A diferença entre as medidas dos tonômetros no grupo A foi estatisticamente significante $(\mathrm{p}<0.0002)$.

CONCLUSÃO: As medidas da pressão intra-ocular com o tonômetro de contorno dinâmico nos pacientes com ceratocone foram significativamente maiores que as medidas do Goldman e menores quando comparadas com o grupo controle. Na ausência de estudos manométricos em olhos com ceratocone, estas baixas medidas com a tonometria de contorno dinâmico podem estar relacionadas com a discrepância entre o raio de curvatura da córnea e a ponta do tonômetro, os baixos valores paquimétricos, ou outras anormalidades da biomecânica corneana relacionadas com o ceratocone avançado.

UNITERMOS: Pressão intra-ocular. Ceratocone. Tonometria de aplanação. Tonometria de contorno dinâmico. Paquimetria. Goldman.

\section{REFERENCES}

1. Goldmann H, Schmidt T. Uber applanationstonometrie. Ophthalmologica. 1957;134:221-42.

2. Doughty MJ, Zaman ML. Human corneal thickness and its impact on intraocular pressure measures: a review and meta-analysis approach. Surv Ophthalmol. 2000;44:367-408.

3. Ehlers N, Bransen T, Sperling S. Applanation tonometry and central corneal thickness. Acta Ophthalmol. 1975;53:34-43.

4. Bhan A, Browning AC, Shah S, Hamilton R, Dave D, Dua HS. Effect of corneal thickness on intraocular pressure measurements with the pneumotonometer, Goldmann applanation tonometer and Tono-pen. Invest Ophthalmol Vis Sci. 2002;43:1389-92.

5. Siganos DS, Papasterigiou GI, Moedas C. Assessment of the Pascal dynamic contour tonometer in monitoring intraocular pressure in unoperated eyes and eyes after LASIK. J Cataract Refract Surg. 2004;30:746-51.

6. Doyle A, Lachkar Y. Comparison of dynamic contour tonometry with Goldman applanation tonometry over a wide range of central corneal thickness. Journal of Glaucoma. 2005;14:288-92.
7. Kaufman C, Bachmann LM, Thiel MA. Intraocular pressure measurements using dynamic contour tonometry after laser in situ keratomileusis. Invest Ophthalmol Vis Sci. 2003;44:3790-4.

8. Colin J, Sale Y, Malet F, Cochener B. Inferior steepening is associated with thinning of the inferotemporal cornea. J Refract Surg. 1996;12:6979.

9. Bohm A, Kohlhaas M, Lerche RC, Bischoff B, Richard G. Measuring intraocular pressure in keratoconus. Effect of the changed biomechanics. Ophthalmologe. 1997;94:771-4.

10. Brooks AM, Robertson IF, Mahoney AM. Ocular rigidity and intraocular pressure in keratoconus. Aust J Ophthalmol. 1984;12:317-24.

11. Kass MA. Standardizing the measurement of intraocular pressure for clinical research. Ophthalmology. 1996;103:183-5.

12. Brandt JD, Beiser JA, Gordon MO, Kass MA. Central corneal thickness in the Ocular Hypertension Treatment Study (OHTS). Ophthalmology. 2001;108:1779-88.

13. Ehlers N, Bramsen T, Sperling S. Applanation tonometry and central corneal thickness. Acta Ophthalmol. 1975;53:1974-83. 